\title{
A NEW ESKIMO GRAMMAR
}

[Review by Hugh Brody* of Kenn Harper's Some aspects of the grammar of the Eskimo dialects of Cumberland Peninsula and north Baffin Island. Ottawa, National Museum of Man, Mercury Series (Ethnology Division Paper No 15), 1974, 94p. \$1.25]

Kenn Harper's title is unduly modest : the grammar may not be complete, but its scope is wide and each of the verb and noun forms included is comprehensively described. It would be an advanced Eskimo speaker indeed who knew a conjugation or declension not included in the book. The feature which distinguishes it from other grammars is the reliance that it places on tables; it looks in fact like the kind of primer with which generations of Latin-learners have been made to struggle. And like those primers, Harper's grammar is not for the 'teach yourself' enthusiast. Rather, it is a companion to the process of learning how the language is spoken from those who speak it. As such it is unsurpassed.

Harper uses the Standard New Orthography originally devised by Raymond Gagné, though he notes that he has adopted some of the modifications to that system contributed by Mick Mallon, who pioneered intensive teaching techniques for Eskimos at the Rankin Inlet school. Use of this orthography may seem a little confusing, for it relies on a limited range of letters. It is, however, as Harper argues in an excellent appendix, a great advance on any of its predecessors-and certainly easier to use than the Syllabic Orthography that Eskimos of much of the Canadian Arctic themselves use. Still, it should perhaps be mentioned that anyone who wishes to exchange letters with Eskimos will have to learn syllabics. The orthography of the grammar book may be good, but it is not the script that the people regard as their own.

Anyone interested in the Eskimo language and who has some knowledge of the language of linguistics can enjoy Harper's book, for he will discover there the wonderful consistency of Eskimo grammar (it is a language without exceptions to its rules) and the wide range of its verbal modes. The book's type-setters are to be congratulated for having made so few typographical errors. It is in every way a thoroughly good grammar.

*Scott Polar Research Institute, Cambridge CB2 1ER.

\section{A MAJOR CARTOGRAPHIC ACHIEVEMENT}

[Review by Peter F. Friend* of the American Geographical Society's Map of the Arctic region. New York, American Geographical Society, 1975. \$12.00]

Anyone interested in polar regions will be delighted that this map has been published. With a scale of 1:5 million and an overall size of $1.53 \mathrm{~m} \times 1.25 \mathrm{~m}$ it is just what many of us have needed for years. The map has been prepared by the Cartographic Division of the American Geographical Society, with support from the National Science Foundation, Exxon and Mobil Oil corporations, and BP Alaska Exploration Inc. It is the latest in a series of 1:5 million maps produced by the society and now covering all the major land areas of the world. The map area includes the whole of Alaska, Greenland and Iceland, Canada north of $60^{\circ}$, Norway, Sweden and Finland north of $64^{\circ}$, and the Soviet Union north of $70^{\circ}$. Because of its rectangular shape it extends considerably south of these latitudes in its corners. The map projection is stereographic and centred on the North Pole; although the scale is exactly 1:5 million along the latitude of $71^{\circ} \mathrm{N}$, it must be adjusted by factors such as 0.98 at the latitude of $80^{\circ} \mathrm{N}$, and 1.12 at the latitude of $47^{\circ} \mathrm{N}$. The measurement of distances generally, great circle courses, and areas, is explained in an inset.

A small inset map shows that extensive land areas of the map have been 'revised in part' using Earth Resources Technology Satellite (ERTS-1) imagery, but there is no hint as to how significant these revisions are. Another inset quotes some hundred or so principal sources used in compiling the map. Various limits of permafrost, sea ice and trees are shown, and the sources quoted.

Much of the recent cartographic advance in the Arctic region has concerned the bathymetry of the seas. Bruce Heezen and Marie Tharp, of Columbia University, have prepared the bathymetric

*Department of Geology, University of Cambridge, Cambridge CB2 3EQ. 